\title{
A INFLUÊNCIA DO BRINQUEDO NA HUMANIZAÇÃO DA ASSISTÊNCIA DE ENFERMAGEM À CRIANÇA HOSPITALIZADA*
}

\author{
Mirian Calíope Dantas Pinheiro** \\ Gertrudes Teixeira Lopes***
}

\begin{abstract}
RESUMO: O estudo do tipo experimental, abjetivou verificar a influência das orientações na humanização da assistência à criança hospitalizada, utilizando bonecos e materiais próprios para terapêutica de venipunção. Apoiou-se em WHALEY e WONG, considerando as experiências desagradáveis e dolorosas do pré-escolar. Participaram da amostra 10 (dez) crianças, que foram avaliadas antes e após as orientações na presença e na ausência da mãe. 'A hipótese nula previu que as crianças orientadas antes dos procedimentos terapêuticos, na presença e/ou ausência da mãe, apresentam os mesmos comportamentos daquelas orientadas. A hipótese nula foi rejeitada ao nivel 0,01 para resultados obtidos fora do intervalo $(-2,58,2,58)$. Concluiu-se que a humanização da criança hospitalizada é possível, a partir das orientações feitas com o auxílio de brinquedo terapêutico e inserção da mãe no tratamento.
\end{abstract}

\begin{abstract}
This study, of the experimental kind, had as its objective to verify the influence of the orientation in humanization of the hospitable children, with use of puppets and proper material for therapeutics of the venipuncture. The support has been WHALEY and WONG, taking into consideration the disagreeable and dolorous experiences of the preschool. The sample consisted of 10 (ten) children, evaluated before and after the orientation in presence and absence of the mother. The null hypothesis foresaw that the children who had been oriented before the proceeding's therapeutics, in presence and/or absence of the mother, presented the same behavior as those who had not been oriented. The null hypothesis has been rejected with a level of 0,01 for results obtained for the interval $(-2,58,2,58)$. It was concluded that the humanization of the hospitable children is possible through the orientation with the aid of therapeutic playthings and the insertion of the mother in the treatment.
\end{abstract}

\section{INTRODUÇÃO}

Humanizar pressupõe o desenvolvimento de algumas das earacterísticas essenciais do ser humano. Dentre elas, as que se fazem urgentes e necessárias em todos os aspectos e setores da vida humana, são a sensibilidade, o respeito e a solidariedade para com os seus semelhantes.

A humanização do sistema de saúde reflete na atualidade uma das grandes preocupações, não só dos nossos dirigentes, mas da própria sociedade que necessita cada vez mais da prestação de serviços de assistência médico-hospitalar, não somente voltada para a tecnologia, eficiência e eficácia gerencial, mas principalmente procurando compreender o homem.

Em meio à crise social, econômica e política em que se encontra o país, a classe mais penalizada e sof rida, sob todos os aspectos, é aquela que compõe a maioria da nossa sociedade, a população carente. E

* Trabalho apresentado como tema livre no 44 Congresso Brasileiro de Enfermagem. Brasilia, DF, 1992.

** Especialista e m Enfermagem Pediátrica e Neonatológica e Especialista em Enfermagem Médico-Cirúrgica, Professora Assistente da Disciplina de Pediatria da Associação Fluminense de Educação - AFE-UNIGRANRIO.

*** Livre-Docente, Mestre e Professora Adjunta do Departamento de Fundamentos de Enfermagem da Faculdade de Enfermagem da Universidade Estadual do Rio de Janeiro - UERJ. Supervisora do Hospital Universitário Gaffrée Guinle da Universidade do Rio de Janeiro - UNIRIO 
dentro deste contexto, podemos destacar aquelas que são mais vulneráveis, as crianças, que, em sua maioria, encontram-se em franco estado de desnutrição, abandono e maus tratos, conseqüentes à situação de miséria em que vivem. Portanto, é para elas que se devem voltar todos os olhares, pois são, neste contexto, as vítimas silenciosas. GRANT ${ }^{(3)}$ afirma que
"não resta a menor dúvida de que, para se defender a infância em qualquer pais, na prática, é necessário promover uma distribuição de renda mais eqüitativa. Para isso, é preciso que se mantenham padrões minimos de nutrição, saúde, ser- viços de saneamento básico, educação e renda familiar. Para a criança, não hasta a sobrevivência. Ela precisa de um mini- mo de assistência da familia e do listado para crescer e desenvolver com dignida- de. O problema é, essencialmente, politi- co"'.

Situando as crianças no universo social $\mathrm{cm}$ que vivemos, podemos constatar algumas diferenças fundamentais, que pesam bastante no tratamento a clas dispensados, especialmente à sua saúdc. Não ć surpresa para os mais leigos ou desinformados, a cxistência de um protecionismo assistencial mascarado. seja ele de ordem financeira ou pcssoal. A mercê dessas condições, muitas vezes motivo de obstáculos, a criança se toma vítima impotcntc que a tudo assiste, sem que lhe caiba o poder de decisiio.

Portanto, visualizando a qucstão com a transparência e a premência que a mcsma assumc. ć iniprescindível humanizar a assistência à criança. para minimizar os sof rimentos a elas causados. como também os distúrbios emocionais produzıdos pela docnça $\mathrm{c}$ pela hospitalização.

Quando se pensa em humanização da assistência. a primeira coisa que nos vem à mentc sĩo os fatores que estão envolvidos nessa hunani/ação. o hospital. a equipe de saúde e o próprio paciente. De todos os profissionais da saúde envolvidos na assistência, o enfermeiro é o que tem maior responsabilidade nesta humanização, uma vez que mantém sob sua responsabilidade um grande número de profissionais de enfermagem, que deverão estar comprometidos com esta assistência, e que por outro por outro lado permanecem longos períodos à serviço do cnfermo

Segundo Paim, Hoelz, Castro. citado por NU $\operatorname{NES}^{(5)}$ e cols:

O enfermeiro lidera sua equipe. respensivel pelas ordens de enfermagem do plano de cuidado do paciente, quer no aspecto de indicação da ordem como prerrogativa exclusiva, quer no aspecto de supervisão e execução de enfermagem. Isto implica a mais profunda responsabilidade à assistência pre.tada ao paciente, visto que esta assistência provém do registro das internações, por ele indicadas, na qualidade de ordens de enfermagem ou prescrições de enfermagem, unidades componentes dos planos de cuidado (p. 31).

Quando se fala de uma equipe humanizada imagina-sc que todos mantêm compromisso e estão dispostos a proporcionar uma assistência sistematizada. fundamentada em princípios científicos, valorizando os aspectos técnicos dos cuidados a serem desenvolvidos e ressaindo-se nas abordagens humanas de compreensão, sentimento de interação entre o enfermciro-criança, ajudando a manter o equilíbrio físicoemocional, através da comunicação que se estabelece pessoa a pessoa e pessoa/ambiente.

As instituições não oferecem ambiente adequado. recursos humanos e materiais quantitativos e qualitativos suficientes, remuneração digna e motivação para o trabalho; oportunidade para os enfermeiros se apcrfeiçoarem em sua área de atuação; condições para cducação cm serviço, relações humanas e cursos, para que cstcs possam exercer as suas funções de uma forma mais humanizada, pois como se sabe, a humani zação depende de condições satisfatórias para executar o trabalho, bem como, integração de esforços da cquipe hospitalar $(1,2)$.

Tem-sc observado no dia-a-dia, no campo de prática. uma assistência de enfermagem prestada a cste contingente especial da sociedade, a criança, que $\mathrm{cm}$ nada o diferencia dos demais conjuntos da população.

A criança muitas vezes é vista na instituição hospitalar como um adulto pequeno, portanto não sendo propiciadas condições diferenciadas na sua assistência, levando-a em algumas situações a manifcstar comportamentos de repúdio à terapêutica prescrita. atitudes de alheamento ou, ao inverso, de agressividade. no seu processo de comunicação com as demais crianças e com a equipe.

Acreditando que a criança é um ser diferenciado, c que a assistência humanizada é possível, a partir do cmpenho $\mathrm{c}$ do conhecimento dos profissionais e em cspecial da enfermagem, é que decidiu-se realizar cstc cstudo, que parece ao mesmo tempo oportuno e relcvantc. contribuindo para a avaliação da assistêncla que $\mathrm{vem}$ sendo prestada, e um repensar dos fatores 
de humanização tão importantes para o equilíbrio bio-psico-social de crianças hospitalizadas.

Isto posto, e na tentativa de dar conta da problemática levantada, questiona-se:

- O que é uma assistência humanizada?

- Quais os comportamentos apresentados pelas crianças submetidas ao procedimento terapêutico de venipunção com e sem orientação prévia na presença ou ausência da mãe?

- Que tipo de preparo deve ser feito?

- Que importância se estabelece na relação de ajuda a criança submetida ao procedimetno terapêutico?

- De que forma estas respostas contribuirão par a humanização da assistência de enfermagem?

O presente trabalho tem os seguintes objetivos:

- Observar as crianças e a equipe de enfermagem durante procedimento terapêutico de venipunção.

- Registrar os comportamentos apresentados pelas crianças durante a execução do procedimento terapêutico na ausência e na presença da mãe antes e depois das orientações.

- Prepararas crianças para o procedimento terapêutico.

- Observar os comportamentos manif estados pela criança durante o procedimento tcrapêutico em resposta às orientações recebidas.

- Demonstrar a importância do preparo da criança na humanização da assistência de enfermagem.

Identificadas as crianças que apresentaram comportamentos de agressividade à terapêutica e à hospitalização, o estudo limita-se a investigar as mudanças de comportamento que a criança venha a expressar a partir da aplicação de um programa de orientação, que visa a humanização da assistência prestada durante o procedimento terapêutico que foi selccionado (administração de medicamento por via endovenosa) tomando por base os pressupostos teóricos de WHALEY e WONG(6), que delineiam as características comportamentais apresentadas pelas crianças na idade pré-escolar durante a hospitalização.

\section{2 - SUPORTE TEÓRICO}

O referencial teórico utilizado neste trabalho está fundamnetado principalmente nos estudos de WHALEY e WONG(6). O referidos autores classificam as reações da criança à hospitalização em termos de fatores estressantes como: ansiedade de separação, perda de controle à lesão corporal e à dor, para os anos de "toddler", pré-escolar, escolar e adolescência respectivamente.

Para o pré-escolar, a reação da Ansiedade de Separação criança-pais, é evidenciada em menor intensidade, pois estes aceitam a separação por breves períodos de tempo. No entanto, na situação de doença e hospitalização, a criança sente dificuldade em lidar com esta situação e responde muitas vezes recusando-se a comer, dormir, chorando baixinho, querendo os pais e indiretamente respondendo de maneira agressiva, quebrando brinquedos, batendo em outras crianças, etc, sem cooperar nas atividades habituais.

A criança apresenta limitações em sua capacidade de compreensão dos fatos e situações vivenciadas, devido ao seu pensamento fantasioso e egocêntrico, apresentando exagero em sua interpretação dos fatos reais. Para explicar a situação de doença e/ou hospitalização, elas são capazes de atribuir este fato a uma punição por mau comportamento, erros reais ou imaginários.

Estas crianças são também vulneráveis à ameaça de lesão corporal. Os procedimentos invasivos, e/ou dolorosos, representam para o pré-escolar preocupações e temores; exemplificando, durante um procedimento terapêutico, como uma simplès aplicação de injeção, podem se mostrar mais preocupados com retirada da agulha do que pela dor real, temendo que o local não se feche, deixando que seus interiores escapem. Na verdade, eles temem, mais que tudo, a mutilação, perda de qualquer parte do corpo, " ...dizer-lhcs que suas amídalas serão removidas pode ser interpretado como tirar sua voz'(6).

Ao final dos 4 anos a criança mantém um certo controle quando experimenta dor, podendo assimilar imposições "os homens valentes não choram". Quando não conseguem ser fortes, chegando a fraquejar, sentem-se culpados e muito envergonhados, em especial, os meninos. É muito comum as queixas somáticas de dor abdominal, sendo este fato bem evidenciado por ocasião do ingresso ao jardim da infância.

São três as reações do pré-escolar ao stress de $d o r$ $e$ medo; agressão física, expressão verbal e dependência. Nas situações em que apresentam comportamentos de agressão, o pré-escolar pode reagir empurrando a pessoa, batendo, chutando e puxando o braço, segurando o equipamento ou trancando-se em lugar seguro, com intuito de adiar ou rejeitar o procedimento terapêutico.

A expressão verbal é uma forma do pré-escolar responder às situações estressantes. Eles poderão agredir com palavras as pessoas que estão prestando-lhes algum cuidado, cxpressar-se com gritos de "sai daqui" 
ou também, podem usar palavras de persuasão, súplica como "por favor, não me dê esta injeção, eu serei bonzinho". Muitas vezes, a criança ao dizer "eu odeio você", pode, naquela ocasião, estar expressando o seu medo e não uma rejeição pela pessoa que a assiste.

De maneira geral, a dependência é uma forma regressiva de comportamentos do pré-escolar, onde ele manif esta ansiedade, dor ou medo. Nessa ocasião os comportamentos mais observados são: agarrar-se aos pais, recusar-se a brincar com outras crianças, voltar à forma não verbal de comunicação, desejar colo e não aceitar ficar sozinha.

\subsection{Situações Desagradáveis da Hospitalização}

Ao somatório de experiências desagradáveis vivenciadas pela criança no confinamento hospitalar, devido a sua condição de doente hospitalizado, é denominada por WHALEY \& WONG "hospitalismo".(6)

Além das situações de separação, a criança doente e internada, econtra-se exposta a inúmeras experiências desagradáveis. A própria enfermidade e a hospitalização acarretam mudanças muito dificeis de serem vividas, necessitando de apoio emocional, caso contrário poderá comprometer sua saúde mental, sem falar nos exames para diagnóstico e tratamento, que a obrigam muitas vezes a enfrentar situações ameaçadoras.

Em virtude de toda problemática da hospitalização, o enfermeiro como parte integrante da equipe hospitalar a serviço da criança doente, deve compreender todas as situações por que passam as crianças, para poderem ajudá-las a adaptar-se ao ambiente hospitalar hostil, bem como minimizar os traumas emocionais advindos do hospitalismo infantil.

WHALEY e WONG(6) enfatizam o valor de se preparar as crianças para enfrentar as adversidades das experiências da hospitalização, auxiliando no seu ajustamento e promovendo melhor aceitação da doença, do tratamento e alívio das tensões.

O enfermeiro deve preparar a criança, explicando e esclarecendo suas dúvidas, de que forma será realizado o procedimento, sua necessidade e quando possível, deixar que a criança manuseie o material.

\subsection{O Comportamento Pessoal e Social do Pré-escolar}

A criança pré-escolar é capaz de verbalizar sua procura de independência devido ao refinamento de seu desenvolvimento físico e cognitivo.
Mantém controle motor e lateralidade, já impõe a mão dominante, pintam, copiam letras, desenham, executam a maior parte de movimentos finos; gosta de freqüentar a escola e sente-se importante. O ingresso no jardim de infância é uma experiência importante, pois promove a socialização, desenvolvendo suas potencialidades e auxiliando na formação de conceitos de linguagem, preparando para o ensino regular.

Nessa idade as crianças são mais suscetíveis às doenças comuns da infância. WHALEY e WONG ${ }^{(6)}$ referem ser o pré-escolar propenso a problemas de saúde, uma vez que a sua imunidade poderá ser baixa, devido à imaturidade do sistema imunológico. As atividades sociais fora de casa, como no caso da escolarização, também predispõem estes às infecções.

\subsection{O Brinquedo como um Recurso para a Assistência de Enfermagem}

WHALEY e WONG(6) mencionam que "brincar é o trabalho das crianças, sendo essencial ao seu bem-estar mental, emocional e social, e, da mesma forma que as necessidades de desenvolvimento, a necessidade de brincar não pára quando a criança adoece ou é hospitalizadas ". É através da brincadeira que ela expressa sua ansiedade, temor e dá ao observador a oportunidade de inf erir significados que muitas vezes são incapazes de verbalizar.

Portanto, é importante que no preparo da criança para enfrentar situações desagradáveis, sejam elaborados programas, os quais utilizem brinquedos para beneficiar a criança no seu crescimento e desenvolvimento, ajustando-a nas situações adversas da doença e hospitalização.

\section{METODOLOGIA}

\subsection{Tipo de Estudo}

Para realização do estudo foi empregado o método experimental com a técnica de grupo único, comparando antes e depois do experimento, mediante observação direta no campo, considerando que a pesquisadora pretendeu intervir na realidade de crianças hospitalizadas, com o propósito de produzir comportamentos compatíveis com a humanização da assistência de enfermagem.

\subsection{População - Amostra}

Participaram da pesquisa as crianças internadas no serviço de clínica médica é um hospital pediátrico 
da rede pública do Município do Rio de Janeiro.

A amostra foi constituída de 10 (dez) crianças com idade entre quatro e cinco anos, de ambos os sexos, porque a criança nesta faixa etária desenvolveu sua capacidade para interagir com outras crianças, com os adultos e o ambiente, utilizando a linguagem simbólica mental, como também verbaliza sua procura de independência, graças ao refinamento do seu desenvolvimento físico e congnitivo(6). térios:

A escolha da amostra atendeu aos seguintes cri-

- Tempo de intemação superior a três dias, sendo que foi necessário uma média de $10(\mathrm{dez})$ dias de observações para obtenção dos dados do estudo.

- Crianças que não apresentassem deficiência mental, auditiva e visual.

- Crianças que não apresentaram comportamentos de agressividade dificultando a execução da terapêutica.

\subsection{Variáveis de estudo}

Selecionou-se como variável independente:

- Comportamentos expressados pelas crianças diante do procedimento terapêutico de administração de medicamentos por via endovendosa.

Como variáveis dependentes:

Relativas as características pessoais.

- Idade, sexo, sono e alimentação.

Relativas à problemática do estudo

- Tipo de agressão expressada durante o procedimento.

- Comportamento apresentado após recebimento das orientações;

Como variável interveniente destacou-se:

- Interferência positiva ou negativa da mãe junto à criança durante o procedimento terapêutico.

Critérios de Avaliação

- Considera-se excelente, se após as orientações, na presença ou na ausência da mãe, 0 a $20 \%$ das crianças apresentarem comportamentos de agressões físicas e dependência.

- Considera-se bom, se após as orientações, na pre- sença ou ausência da mãe, 21 a $40 \%$ das crianças apresentarem comportamentos de agressões físicas e dependência.

- Considera-se regular quando após as orientações, na presença ou na ausência da mãe, acima de 41 a $60 \%$ das crianças apresentarem comportamentos de agressão física e dependência.

- Considera-se deficiente quando, após as orientações, na presença ou na ausência da mãe, acima de $61 \%$ das crianças apresentarem comportamentos de agressão física e dependência.

Para avaliação das variáveis relativas ao comportamento apresentado pelas crianças, antes e após o experimento, com a presença da mãe, foi elaborado um crivo de avaliação com 18 (dezoito)itens, sendo atribuído o valor numérico de 1,0 (um ponto) para as respostas afirmativas.

O instrumento elaborado com as variáveis agressão física, expressão verbal e dependência teve a seguinte organização:

Quadro 1 - Crivo de avaliação das questões referentes a fase de agressões físicas, expressões verbais e dependência segundo o número de pontos obtidos e previstos.

\begin{tabular}{clc}
\hline Ordem & Fase de Agressăo Fisica & $N^{\circ}$ de pontos previstos \\
\hline 01 & Bate & 1,0 \\
02 & Chuta & 1,0 \\
03 & Puxa o braço & 1,0 \\
04 & Empurra & 1,0 \\
05 & Segura o Equipamento & 1,0 \\
06 & Se esconde & 1,0 \\
07 & Quebra ou joga os brinquedos & 1,0 \\
\hline Total & \multicolumn{2}{c}{} \\
\hline \multicolumn{3}{c}{} \\
\hline Ordem & Fase de Expressăo & $N^{0}$ de pontos previstos \\
\hline 01 & Chora & 1,0 \\
02 & Grita & 1,0 \\
03 & Ameaça & 1,0 \\
04 & Discute & 1,0 \\
05 & Culpa & 1,0 \\
06 & Exige & 1,0 \\
\hline Total & & 6,0 \\
\hline \multicolumn{2}{l}{} \\
\hline Ordem & Fase de Dependência & $N^{\circ}$ de pontos previstos \\
\hline 01 & Agarra-se aos pais & 1,0 \\
02 & Chora baixinho & 1,0 \\
03 & Deseja colo & 1,0 \\
04 & Recusa-se a brincar & 1,0 \\
05 & Recusa-se a ficar sozinho & 1,0 \\
\hline Total & & 5,0 \\
\hline
\end{tabular}


Com a finalidade de testar as hipóteses e as variáveis, utilizou-se 1 (um) formulário (em anexo) composto de três blocos: um relativo às características individuais, outro abordando hábitos de vida e o terceiro referente aos comportamentos apresentados.

A primeira parte, relativa às características individuais da criança, é composta de dois itens referentes a idade e sexo.

A segunda parte referiu-se a hábitos de vida, composta de dois tópicos com as seguintes variáveis: sono e alimentação.

A terceira, referente aos comportamentos apresentados pelas crianças, frente ao procedimento terapêutico de administração de medicamentos por via endovenosa, antes e depois do experimento, é composta dos itens relacionados a agressão física, expressão verbal e dependência.

\subsection{Coleta de Dados}

O estudo foi realizado durante todo o ano de 1991, tendo sido coletados os dados nos meses de agosto a outubro, onde a pesquisadora permaneceu na clínica pediátrica nos períodos da manhã e tarde, observando as crianças, aplicando o experimento e coletando os dados. A coleta de dados foi realizada em três fases:

$\mathrm{Na}$ primeira fase, a pesquisadora observou as crianças durante os dias que foram necessários para evidenciar duas punções venosas, e constatar os comportamentos agressivos, expressados pelas crianças durante o procedimento terapêutico, na presença e ausência da mãe.

$\mathrm{Na}$ segunda fase foi aplicado o instrumento, com a finalidade de colher dados sobre as características pessoais, e avaliar os comportamentos de rejeição manifestados pelas crianças. Tais comportamentos dificultavam a execução da terapêutica. Vale salientar, que nesta fase não houve intervenção da pesquisadora.

$\mathrm{Na}$ terceira fase, foram feitas as orientações, ou seja, a aplicação do experimento simultaneamente às observações e registros dos comportamentos apresentados pelas crianças, diante da punção venosa. $\mathrm{O}$ registro dos comportamentos foi obtido com a reaplicação do instrumento anteriormente citado.
Considerando o reduzido número da amostra, os dados foram processados manualmente. Utilizou-se o tratamento descritivo dos dados, com a frequiência absoluta. Foram calculados medida de tendência central, desvio padrão das notas atribuídas ao comportamento das crianças antes e após a implementação das orientações, baseadas nas reações comportamentais contidas no crivo de avaliação das variáveis.

A hipótese substantiva previu não haver mudanças no comportamento apresentado pelas crianças hospitalizadas submetidas ou não às orientações antes do procedimento terapêutico, na presença ou na ausência da mãe.

Elaborou-se as hipóteses estatísticas sob as formas nula e alternativa, a saber:

$\mathrm{H}_{0}$ - As crianças orientadas antes do procedimento terapêutico, na presença ou na ausência da mãe apresentam os mesmos comportamentos de agressividade física, expressão verbal e dependência, daquelas não orientadas

$\mathrm{H}_{1}$ - As crianças orientadas antes do procedimento terapêutico, na presença e na ausência da mãe, apresentam comportamentos de menor agressividade, comunicando suas emoções, cooperando durante o procedimento, mostrando-se mais independente e manif estando segurança

O teste de hipótese previu o cálculo das médias e o desvio padrão das diferenças dos escores obtidos antes e após as orientações, observando a seguinte fórmula:

$$
s=\sqrt{\frac{\sum D^{2}}{n}}-\left(\overline{\mathrm{X}}_{\mathrm{i}}-\overline{\mathrm{X}}_{\mathrm{t}}\right)^{2}
$$

onde:

$\mathrm{S}=\mathbf{o}$ desvio padrão das distribuições dos escores das diferenças (antes / depois).

$\mathrm{D}=\mathrm{a}$ diferença dos resultados (antes / depois).

$\mathrm{n}=\mathrm{o}$ tamanho da amostra.

$\bar{X}_{\mathrm{i}}=$ média aritmética dos resultados antes das orientações.

$\bar{X}_{t}=$ média aritmética dos resultados depois das orientações

Estabeleceu-se o grau de liberdade igual a 9, comparando a razão do Tc calculado obtido pela seguinte relação $\left.\bar{X}_{i}-\bar{X}_{t}\right) /$ Zdif onde Zdif é o quociente entre o desvio padrão e a raiz quadrada do número de graus de liberdade e $\mathrm{Tt}$ tabelado estatisti- 
camente definido pela distribuição de probabilidade t-Student, verificando-se que a hipótese $\mathrm{H}_{0}$ seria rejeitada se o escore obtido por $\mathrm{S}$ estivesse fora do intervalo $(-2,58,2,58)$ ao nível de 0,01 .

\subsection{Programa de orientação}

O experimento foi elaborado contendo 4 (quatro) itens, a saber: conteúdo, objetivos, estratégia e recursos.

O conteúdo é relativo ao procedimento terapêutico por via endovenosa. O objetivo justifica a necessidade da importância de se fazer as orientações às crianças, com vistas à humanização da assistência. A estratégia é uma maneira pela qual a pesquisadora orientou as crianças que participaram do estudo. Os recursos foram todos os materiais e pessoal necessário para o preparo das crianças. Este programa foi realizado em duas etapas:

A primeira etapa foi desenvolvida antes e durante o procedimento terapêutico de administração de medicamento por via endovenosa, contendo as fases a seguir:

- apresentação do material;

- demonstração da técnica de venipunção através da dramatização da situação com bonecos (brincadeira do faz de conta);

- intervenção da pesquisadora momentos antes do procedimento;

- reforço durante o procedimento.

Na segunda etapa realizada com a criança após o procedimento terapêutico foram avaliados e registrados os resultados.

Para dar conta do conteúdo, contou-se com os pressupostos teóricos de Bellack citado por MARTINS, OHKI e FELLI ${ }^{(4)}$ sendo elaborado um programa de orientação que se segue:

a. CONTEÚDO - Administração de medicamentos por via endovenosa.

b. OBJETIVOS - Levar a criança a uma melhor aceitação da terapêutica; minimizar o stress da agressão terapêutica; levar a criança a familiarizar-se com o material; dissiparo medo do desconhecido; proporcionar à criança oportunidade de extravasar sua agressividade; proporcionar momentos de lazer; facilitar a execução da técnica; auxiliar na compreensão do procedimento, levando a criança a concretização do imaginável ao real e proporcionar maior segurança. c. ESTRATÉGIAS - Informar a criança sobre os procedimentos a que vai se submeter; explicar a finalidade do mesmo; apresentar o material para a criança, dizendo o que é, e para que serve; deixar que a criança manipule o material; dramatizar com a ajuda de bonecos, demonstrando a técnica; deixar que a criança execute o procedimento, não interferindo na sua execução, a menos que seja solicitado; estar ao seu lado durante a experiência, demonstrando interesse, amore carinho; deixar a criança expor sua opinião e desejo; proporcionar segurança emocional, conquistar sua confiança e promover a estimulação tátil; ser enérgico quando necessário; pedir sua colaboração durante o procedimento; elogiar o êxito e reintegrar a criança às rotinas da unidade após a execução da terapêutica.

d. RECURSOS - Os pesquisadores, equipe de saúde e a criança; material de venipunção, medicamentos da instituição e bonecos de pano.

\section{RESULTADOS E DISCUSSÕES}

A análise da idade e sexo das crianças investigadas, demonstrou a predominância daquelas com 5 (cinco) anos do sexo masculino, num total de 6 (seis); 3 (três) do sexo feminino e 1 (um) do sexo masculino com 4 anos. Não compareceram crianças do sexo feminino com 4 anos.

Tabela 1 - Distribuição da amostra de acordo com a idade e sexo, Rio de Janeiro, 1991.

\begin{tabular}{lccc}
\hline \multirow{2}{*}{ Idade } & \multicolumn{2}{c}{ Sexo } & Total \\
\cline { 2 - 3 } & Masculino & Feminino & 01 \\
\hline 4 anos & 01 & - & 09 \\
\hline 5 anos & 06 & 03 & 10 \\
\hline Sub-total & 07 & 03 & \\
\hline
\end{tabular}

O sexo masculino predominou, bem como a idade de 5 anos. Durante as observações evidenciou-se uma diferença nos comportamentos apresentados por ambos os sexos, em termos de maior ou menor agressividade. Os meninos apresentavam maior agressividade que as meninas. Este fato pareceu-nos muito significativo no decurso das observações.

Pode-se inferir que o sexo masculino e a idade a partir dos 4 anos predispõem a criança à agressividade, especial mente quando se impõem situações indesejadas como é o caso da hospitalização e das terapêuticas dolorosas. 
Tabela 2 - Distribuição da amostra segundo o comportamento da criança, início (primeira fase) e término (terceira fase) das observações, referente a sono e alimentação, Rio de Janeiro, 1991.

\begin{tabular}{|c|c|c|}
\hline $\begin{array}{c}\text { Sono } \\
\text { e Alimentaçåo }\end{array}$ & $\begin{array}{l}\text { Início das } \\
\text { bservaçóes } \\
\text { (Sim) }\end{array}$ & $\begin{array}{l}\text { Término das } \\
\text { Observaçōes } \\
(\text { Sim) }\end{array}$ \\
\hline Recusa-se a dormir & 08 & \\
\hline Acorda durante a noite & 08 & 08 \\
\hline Tem sono agitado & 07 & 02 \\
\hline Recusa-se a comer & 08 & - \\
\hline Alimenta-se na ausência da mấ & láe 07 & - \\
\hline Alimenta-se com ajuda & 06 & - \\
\hline
\end{tabular}

No final das observações nenhuma das 10 (dez) crianças apresentaram comportamentos relativos às alternativas: recusar a dormir, comer, alimentar-se com ajuda; 8 (oito) continuaram a acordar durante a noite e alimentar-se na ausência da mãe; apenas 2 (duas) crianças continuaram apresentando agitação durante o sono. (Tabela 2)

No início das observações foram evidenciados muitos comportamentos de recusa por parte das crianças. Nesta fase constatou-se com maior freqüência os comportamentos de recusa a dormir, comer e acordar durante a noite.

WHALEY e WONG(6) mencionam que o pré-escolar manifesta sutilmente comportamentos de protestos devido à ansiedade de separação, ocasionada pela doença e hospitalização e os expressam nas atitudes de recusar-se a comer e dificuldades para dormir.

Entende-se que, muitas vezes, a criança na idade pré-escolar apresenta estes comportamentos na tentativa de obter ajuda, um pedido de socorro, ou mesmo chamar a atenção. As crianças em estudo, além de apresentar os comportamentos próprios da idade, manifestavam atitudes de protesto à situação imposta pela doença e a hospitalização, rejeitando em consequência o novo ambiente, as pessoas e a terapêutica.

Ao final das observações, as situações relativas à recusa a dormir durante a noite, comer e alimentar-se com ajuda não foram evidenciadas. Pode-se inferir que as crianças foram aos poucos entendendo a nova situação e recuperando a sua independência, mantendo uma evolução positiva em seu comportamento. Acredita-se que, quando a criança é orientada, recebe carinho e apoio, sente-se mais segura e aceita melhor as terapêuticas, cooperando nas atividades habituais.

Deve-se salientar que a orientação das mães e/ou familiares constitui fator decisivo no apoio à criança e portanto na manutenção do seu equilíbrio emocional.

Constatou-se ser a mãe elemento importante na recuperação e adaptação da criança, por ocasião do procedimento terapêutico de administração de medicamentos por via endovenosa (venipunção), mas somente quando orientada devidamente. A ansiedade e angústia manifestadas pela mãe muitas vezes são percebidas e transmitidas ao filho, só podendo ser amenizada se ela participar e receber explicações a respeito dos procedimentos adotados com o filho.

\section{1 - Características dos comportamentos}

Os comportamentos foram caracterizados conforme as agressões físicas, expressão verbais, dependência, descritas por WHALEY e WONG(6). Analisando-se as agressões físicas expressadas pelas crianças antes das orientações na presença da mãe foram obtidos os seguintes resultados, expresso na Tabela 3.

Tabela 3 - Distribuição da amostra de acordo com as agressões físicas expressadas durante a punção venosa, antes e depois das orientações, na presença e na ausência da mãe, Rio de Janeiro, 1991.

\begin{tabular}{|c|c|c|c|c|}
\hline \multirow{3}{*}{$\begin{array}{l}\text { Agressão } \\
\text { Física }\end{array}$} & \multicolumn{2}{|c|}{ Antes das Orientaçōes } & \multicolumn{2}{|c|}{ Depois das Orientaçð̄es } \\
\hline & $\begin{array}{l}\mathrm{Na} \\
\text { presença } \\
\text { da måe }\end{array}$ & $\begin{array}{l}\mathrm{Na} \\
\text { ausência } \\
\text { da mâe } \\
\end{array}$ & $\begin{array}{l}\text { Na } \\
\text { presença } \\
\text { da måe }\end{array}$ & $\begin{array}{l}\text { Na } \\
\text { ausência } \\
\text { da måe }\end{array}$ \\
\hline & Sim & Sim & Sim & Sim \\
\hline Bate & 06 & 04 & 01 & - \\
\hline Chuta & 08 & 05 & - & - \\
\hline Puxa braço & 10 & 09 & 01 & - \\
\hline Empurra & 10 & 08 & 02 & - \\
\hline Segura Eq. & 09 & 08 & 02 & - \\
\hline Esconde-se & 05 & 03 & 01 & 01 \\
\hline Joga bring. & 05 & - & 01. & - \\
\hline
\end{tabular}

* Esta tabela nåo apresenta total por permitir mais de uma opçåo

\section{Antes das Orientações}

Considerando as agressões físicas na presença da mãe, os dados obtidos demonstram que: todas as 10 (dez) crianças puxavam o braço e empurravam, 9 (nove) seguravam o equipamento durante a execução da terapêutica; 8 (oito) manifestavam o comporta- 
mento de chutar as pessoas e os objetos à sua volta; 6 (seis) se expressavam batendo na mãe, nos elementos da equipe e em si próprio e 5 (cinco) escondiam-se e jogavam os brinquedos, respectivamente.

Na ausência da mãe os comportamentos evidenciados foram: 9 (nove) crianças puxavam o braço durante o procedimento terapêutico; 8 (oito) empurravam e seguravam o equipamento, respectivamente; 5 (cinco) chutavam; 4 (quatro) batiam; 3 (três) se escondiam. Nenhuma criança manifestou o comportamento de jogar os brinquedos.

\section{Depois das orientações}

Os comportamentos expressados pelas crianças na presença da mãe indicam uma redução acentuada na agressividade como demonstram os resultados: 2 (duas) crianças continuaram segurando o equipamento e empurrando; 1 (uma) expressou-se batendo, puxando o braço, escondendo-se e jogando os brinquedos. Merece destacar que nenhuma criança expressou-se chutando.

$\mathrm{Na}$ ausência da mãe apenas uma $(01)$ criança continuou escondendo-se no momento da intervenção terapêutica.

O resultados das agressões físicas na ausência ou na presença das mães, antes de efetuar-se as orientações. expressam comportamentos de maior agressividade, enquanto que, após a implementação do experimento, constatou-se uma expressiva redução destes, o que cxpressa a possibilidade de humanizar a assistência, a partir das orientações feitas às crianças com cxtensão às mãcs acompanhantes.

Esscs resultados confirmam WHALEY e WONG(6), que instniem sobre a importância da orientação para criança hospitalizada. Além destas constatações, a autora pode observar no decorrer do estudo. que os comportamentos não se restringiam a um ato de passividade, mas principalmente a uma participação efetiva.

As crianças, ao manipularem material na sala de curativo. que se achava desativada, no leito ou na sala de recreação. copiavam o modelo de verbalização c atitudes quando repetiam a técnica com os bonecos sob a supervisão da pesquisadora, não deixando de observar condições importantes como gotejamento. locais das punções, algodão com álcool. garrote c todos os componentes necessários. radrapo, a braçadeira, avisando o término das infusões, presença de sangue no escalpe e algumas vezes, incentivando e vigiando outras crianças que não faziam parte do estudo. As mães participaram efetivamente do experimento. Inicialmente tinham atitudes similares às crianças, expressando seus medos e ansiedades. Após serem orientadas e participarem da demonstração com bonecos, ajudavam consideravelmente os filhos e a equipe.

É importante enfatizar que a equipe de enfermagem, ao se inserir no trabalho, também assumiu atitudes diferenciadas no tratamento à criança, considerando o processo de humanização fundamental para o equilíbrio emocional da mesma. Atitudes agressivas foram paulatinamente substituídas por formas de carinho e compreensão.

A comunicação na unidade é outro fato que merece destaque, em virtude das mudanças observadas, no sentido de interação entre as mães-crianças-pesquisadora e equipe de enfermagem.

Infere-se diante desses achados, que é viável a humanização da assistência à criança hospitalizada. se a equipe de saúde sair do seu papel autoritário e assumir postura humanística junto à criança e família. compartilhando de suas angústias e medos no momento crítico vividos por ambos.

Analisando-se as expressões verbais produzidas pelas crianças antes das orientações na presença e na ausência da mãe, constatou-se os seguintes resultados:

Tabela 4 - Distribuição das crianças segundo as expressões verbais expressadas durante a punção venosa, antes e depois das orientações, na presença e ausência da mãe, Rio de Janeiro, 1991.

\begin{tabular}{|c|c|c|c|c|}
\hline \multirow{3}{*}{$\begin{array}{c}\text { Expressăo } \\
\text { Verbal }\end{array}$} & \multicolumn{2}{|c|}{ Antes das Orientações } & \multicolumn{2}{|c|}{ Depois das Orientaçס̄es } \\
\hline & $\begin{array}{l}\mathrm{Na} \\
\text { presença } \\
\text { da mãe }\end{array}$ & $\begin{array}{l}\text { Na } \\
\text { ausência } \\
\text { da mãe }\end{array}$ & $\begin{array}{l}\mathrm{Na} \\
\text { presença } \\
\text { da mãe }\end{array}$ & \begin{tabular}{|l} 
Na \\
ausência \\
da mãe
\end{tabular} \\
\hline & Sim & Sim & Sim & Sim \\
\hline Chora & 10 & 09 & 08 & 06 \\
\hline Grita & 09 & 04 & - & - \\
\hline Ameaça & 09 & 09 & 01 & 01 \\
\hline Discute & 10 & 08 & 08 & 07 \\
\hline Culpa & 10 & 08 & 10 & 10 \\
\hline Exige & 10 & 09 & 02 & 01 \\
\hline
\end{tabular}

Algumas crianças cooperavam retirando o espa- 


\section{Antes das Orientações}

As agressões verbais na presença da mãe foram as seguintes: todas as $10(\mathrm{dez})$ choravam, discutiam, culpavam-se e mostravam-se exigentes; 9 (nove) gritavam e ameaçavam.

Os comportamentos expressados pelas crianças na ausência da mãe foram: 9 (nove) crianças choravam, ameaçavam e exigiam; 8 (oito) discutiam e culpavam-se e apenas 4 (quatro) gritavam.

\section{Depois das Orientações}

Os comportamentos expressados pelas crianças na ausência da mãe, demonstram os resultados: 10 (dez) culpavam-se, 8 (oito) choravam e discutiam respectivamente; 2 (duas) continuavam só uma ameaçava e ao final nenhuma gritou na presença da mãe.

Podemos constatar que na ausência da mãe, 10 (dez) culpavam-se, 7 (sete) discutiam, 6 (scis) choravam, 1 (uma) ameaçava e exigia. Nenhuma expressão gritar foi identificado.

A leitura destes resultados indica que as crianças manifestavam seus sentimentos utilizando-se de todas as formas de expressões verbais preconizadas por WHALEY e WONG ${ }^{(6)}$. Após as orientações constatou-se uma significativa redução desta forma de expressão, sendo que o grito não foi constatado em nenhum momento da terapêutica venosa, assim como as ameaças e as exigências quase desapareceram.

Observou-se que houve mudança na maneira como a discussão acontecia, que estava mais para o adiamento da terapêutica, do que para agressão.

Dentre os fatores que produziam as reações verbais estavam as pessoas de branco, ou qualquer material de punção venosa que as mesmas transportassem. Com relação às expressões pronunciadas estavan: "cla vai me furar", "eu estou com medo", "espera, deika eu falar", "agora não", "não, por favor, não me fura".

$\mathrm{O}$ grito anteriormente associado ao choro desapareceu, e o choro passou a ser manifcstado como uma forma de cooperação, quando a criança perguntava de que forma cla poderia ajudar. Mais uma vez a criança repetia todas as orientações reccbidas durante o experimento. o que amenizava o scu sof rimento e instituía o tratamcmo sem maiores traumas.
Tabela 5 - Distribuição dos comportamentos de dependência expressados pelas crianças antes e depois das orientações, na presença e ausência da mãe, Rio de Janeiro, 1991.

\begin{tabular}{|c|c|c|c|c|}
\hline \multirow{3}{*}{$\begin{array}{l}\text { Depen- } \\
\text { déncia }\end{array}$} & \multicolumn{2}{|c|}{ Antes das Orientaçðes } & \multicolumn{2}{|c|}{ Depois das Orientaçoes } \\
\hline & $\begin{array}{l}\mathrm{Na} \\
\text { presença } \\
\text { da máe }\end{array}$ & $\begin{array}{l}\mathrm{Na} \\
\text { ausência } \\
\text { da måe }\end{array}$ & $\begin{array}{l}\mathrm{Na} \\
\text { presença } \\
\text { da måe }\end{array}$ & $\begin{array}{l}\text { Na } \\
\text { ausência } \\
\text { da máe }\end{array}$ \\
\hline & Sim & Sim & Sim & Sim \\
\hline $\begin{array}{c}\text { Agarra-se } \\
\text { aos pais }\end{array}$ & 06 & 06 & 02 & - \\
\hline $\begin{array}{l}\text { Chora } \\
\text { baixinho } \\
\text { Deseja }\end{array}$ & 09 & 07 & 06 & 05 \\
\hline colo & 08 & 06 & 01 & - \\
\hline $\begin{array}{c}\text { Recusa-se } \\
\text { a brincar } \\
\text { Recusa-se }\end{array}$ & 10 & 08 & 01 & - \\
\hline a ficar só & 09 & 08 & 03 & - \\
\hline
\end{tabular}

De acordo com a Tabela 5 , os comportamentos de dependência manif estados pelas crianças assim se expressam:

\section{Antes das Orientações}

Os comportamentos de dependência manifestados pela criança, na presença da mãe revelam que, 10 (dez) crianças recusavam-se a brincar, 9 (nove) recusavam-se a ficar sozinhas e choravam baixinho, 8 (oito) manifestavam desejo de ficar no colo e 6 (seis) agarravam-se às mães e desejavam colo respectivamente.

\section{Depois das Orientações}

Constatou-se na presença da mãe uma considerável redução no comportamento de dependência: 6 (seis) crianças continuavam chorando baixinho, 3 (três) recusavam-se a ficar sozinhas, 2 (duas) continuavam agarrando-sc às mães e 1 (uma), desejava colo e recusava-se a brincar, respectivamente.

No que tange ao comportamento de dependência constatou-se que antes das orientações, as crianças apresentavam-se inseguras e dependentes das mães, inclusive para se alimentar. O chorar baixinho, recusar-se a brincar e ficar sozinha, predominaram na presença c na ausência da mãe.

Após as orientações o quadro de dependência sofreu profundas modificações, chegando ao nível zero. Apenas o choro baixinho permaneceu em cinco 
crianças, podendo ser visualizado como um comportamento normal, considerando ser uma terapêutica dolorosa.

WHALEY e WONG ${ }^{(6)}$, confirmam esses resultados, como forma regressiva própria do pré-escolar, as quais se exacerbam na presença de dor e medo.

Observou-se no presente estudo que as crianças em algumas situações atribuíram, seu sof rimento às mães (expressão de culpa), rejeitando a presença destas e muitas vezes agredindo-as durante a execução da terapêutica. Por outro lado, algumas mães procuravam acariciar e consolar os filhos, enquanto outras comportavam-se agressivamente, ameaçando bater e ir embora, por exemplo.

É importante destacar que as mães antes agressivas no trato com as crianças, também assumiram atitudes colaborativas com a equipe e a criança.

A condição de realidade era sempre apresentada à mãe e à criança, o que gerava um ambiente de confiança e em nenhuma situação era estimulada a fantasia destes, levando a uma diminuição da dependência, agressividade e stress.

Mais uma vez se confirma que a humanização da assistência criança no hospital é possível, desde que a equipe e a mãe sejam transparentes no trato com a criança, pois a leitura dos resultados evidencia esta constatação.

A seguir, são apresentados os desvios padrão dos escores atribuídos às agressões físicas, expressão verbal e dependência, antes e após as orientações, na presença e na ausência da mãe, considerando o cálculo da média de cada momento. Conforme pode ser observado, antes das orientações os valores atingidos foram superiores àqueles obtidos após as orientações.

Tabela 6 - Desvio padrão dos escores atribuídos as agressões físicas expressão verbal e dependência das crianças, na presença ou ausência das mães, Rio de Janeiro, 1991.

\begin{tabular}{l|c|c}
\hline \multirow{2}{*}{ Comportamento } & \multicolumn{2}{|c}{ Desvio Padrăo } \\
\cline { 2 - 3 } & $\begin{array}{l}\text { Antes das orienta- } \\
\text { çōes na presença e }\end{array}$ & $\begin{array}{l}\text { Após as orienta- } \\
\text { çós na presença e } \\
\text { na ausência da măe }\end{array}$ \\
na ausência da măe \\
\hline Agressão física & 8,13 & 5,47 \\
Expressăo verbal & 9,23 & 4,00 \\
Dependência & 8,24 & 6,07 \\
\hline
\end{tabular}

A hipótese nula previu que as crianças orientadas antes do procedimento terapêutico, na presença e ausência da mãe, apresentavam os mesmo compor- tamentos daquelas não orientadas.

Estabeleceu-se o grau de liberdade 9, e a diferença entre o Tc calculado e o Tt tabelado, se o escore obtido por S (desvio padrão) estivesse fora do intervalo $(-2,58,2,58)$. Assim obteve-se $S=10,07$, portanto fora do intervalo, rejeitando-se $\mathrm{H} 0$, ao nível de 0,01 .

\section{CONCLUSÕES}

Os dados levantados permitem conlcuir:

- Os comportamentos apresentados pelas crianças sumbetidas ao procedimento terapêutico escolhido para investigação, são relativos à agressão física, expressão verbal e dependência.

- Os comportamentos mais evidenciados antes das orientações, na presença e na ausência da mãe, foram: puxar o braço, empurrar, segurar o equipamento, chorar, gritar, sentir-se culpada, tornar-se exigentes e recusar-se a brincar: chorar baixinho, dese jar colo e recusar-se a ficar sozinha.

- Após as orientações, os comportamentos sof reram prof undas mudanças, sendo que a maioria desapareceu, permanecendo apenas manifestações como: discute, chora, sentimento de culpa, chora baixinho.

- A instrumentação por meio de bonecos e materiais concretos oportuniza a criança a associar o imagninário ao real, compreender as condições adversas e cooperar no tratamento.

- A dramatização da situação vivenciada pela criança, através do uso dos bonecos, favorece a diminuição do estresse decorrente da terapêutica e da hospitalização.

- O preparo e orientação da mãe é condição indispensável para um trabalho cooperativo e humanístico ao binômio mãe-filho.

- Os fatores determinantes dos comportamentos agressivos devem ser conhecidos por todos os membros da equipe de saúde, para que estes possam minorar os traumas da hospitalização.

- Uma assistência humanizada provém de esforços conjuntos da equipe, aliando-se as boas condições de ambiente de trabalho; pessoal treinado e qualificado para este fim, na promoção do cuidado bio-psico-social completo para a criança e a família. A interação entre equipe-criança-família é condição básica para resolução dos problemas . para atender às necessidades da criançą, benefi- 
ciando não só a condição física, mas também a emocional.

- Deve ser compromisso dos profissionais propiciar às crianças condições de crescimento e desenvolvimento normal e equilíbrio emocional, atentando para uma assistência sistematizada e individualizada, percebendo a criança como um todo e em constante interação com o ambiente dinâmico do hospital, ou seja, holisticamente.

- Uma assistência humanizada não é só condição técnica, mas prioritariamente a solidariedade, o amor e o respeito pelo ser humano, uma vez que, a criança em sua condição indefesa e instável emocionalmente, busca em outrem apoio carinho e compreensão.

- De acordo com o critério de avaliação estabelecido, e tomando por base o crivo de avaliação das variáveis, considera-se as orientações quanto a agressão e tomando por base o crivo de avaliação das variáveis, considera-se que as orientações quanto a agressão física atingiram o conceito de Excelente, uma vez que apenas $14,28 \%$ apresentara esse comportamento. No que se refere à dependência, o conceito atingido foi Bom o que equivale a $36 \%$ dos comportamentos expressados.

- A expressão verbal sof reu modificações no seu conteúdo, ressaindo-se a expressão de culpa, que de acordo com a observação da autora pode ser traduzido numa atitude de adiamento da situação terapêutica e desculpa por ter chorado.

\section{SUGESTÕES}

Aos enfermeiros:

- Tenham bem claro o conceito de humanização e a sua importância para que possam empregar no dia-a-dia com as crianças hospitalizadas.

- Utilizem técnicas com auxílio de bonecos e materiais de uso hospitalar, dramatizando as situações concretas com o intuito de proporcionar compreensão por parte da criança.

- Promovam orientações antes, durante e após experiências dolorosas como a venipunção.

- Proporcionem explicações sobre a doença e hospitalização, procedimentos terapêuticos, exames, rotinas hospitalar, etc, à criança e à mãe

- Assistam as crianças hospitalizadas com espírito humanitário, transmitindo-lhes afeto, carinho e respeito.

- Orientem as mães, para que elas se associem à equipe e passem a ser um elemento facilitador do processo assistência.

- Vejam as crianças como seres que são, inserindoas no tratamento de forma participativa.

- Expliquem às crianças os procedimentos que serão realizados, solicitando sua co̊operação.

À equipe de saúde:

- Que haja interação entre seus membros e a mãe, no sentido de que a assistência à criança possa se dar em um clima de afeto e companheirismo.

\section{REFERÊNCIAS BIBLIOGRÁFICAS}

1. ANDRADES, I. Orientação Infantil. 6. ed. Petrópolis: Vozes, p. 323-330, 1985.

2. ACHCAR, M.C.H. Humanização do hospital. rev. Enf. Atual, ano $\mathrm{I}, \mathrm{n}^{\circ}$ 5, mai/jun, 1979.

3. GRANT, J.A. Situação mundial da infâncıa. Brasilia: UNICEF, p. 1-40, 1984.

4. MARTINS, D. M. R., OHKI, A. E., FELLI, V. E. M. Assistência de enfermagem a crianças hospitalizadas quando enf erntam situações desagradáveis (parte I). Rev. Esc. Enf. USP., v. 2, n. 13, p.157-169, 1979 .
5. NUNES, D. N. et al. Aspectos da atividade assistêncial de enfermagem na unidade de internação pediátrica. Rev. Bras. Enf., R.S., n. 36, p. 29-37, 1983.

6. WHALEY. E. H. \& WONG, D. L. Enfermagem pediátrica. Rio de Janeiro: Guanabara, 895p, 1989.

\section{BIBLIOGRAFIA}

1. ÂNGELO, M. Visitas restritas a criança hospitalizada: uma barreira para a intervenção mãe-fillho. Rev. Esc. Enf. USP, v. 3 , n. 19, p. 213-223, 1985

2.

Brinquedo: um caminho para a compreensão da criança hospitalizada. Rev. Esc. Enf. USP., v.3, n.19, p.213223,1985
3. BEANI, T. C. A escuta do silêncio: um estudo sobre a linguagem do pensamento de Heidegger. São Paulo: Cortez / Autores Associados, 1981, p. 29-31.

4. BROWN, M. S. \& MURPHY, M. A. Pediatria em ambulatório para enfermeiras. São Paulo: 1980, p. 255-263.

5. CAMARGO, M. Étıca, vida e saúde. 7. ed. Petropólis: Vozes, 1983. 
6. DIDIER, M. G. S. L. Brincar faz parte do crescer. Recif e: Universidade Católica de Pernambuco, 1977.

7. DUARTE, E. R. M. et al. A utilização de brinquedos na sala de recuperação: um recurso a mais para assistência à criança. Rev. Bras. Enf., Brasília, v. 1, n. 40, p. 74-81, 1987.

8. FARIAS, F.L.R. Alterações comportamentais ocasionadas para separação mãe-filho durante a hospitalização da criança. Rev. Bras. Enf., Brasilia, v. 2, n. 41, p. 107-122, abr/jun. 1988.

9. JERSILD, A Psicologia da criança, $5^{2}$ ed. Belo Horizonte: Itatiaia. 1966.

10. LIMA, A. M. et al. A criança e a familia frente à hospitalização. Rev. Enf. Moderna, v. 3, jul/set 1985.

11. LISBOA, A.M.J. Programa de hospitalização conjunta mãefilho. J. Ped. p. 38-191, 1973

12. ; TRENCH, M. H. e HECMAIER, M. Assitência de enf ermagem a crianças hospitalizadas quando enf rentam situações desagradáveis (parte II) Rev. Esc. Enf. USP., v. 3, n.13, p.287-299, 1979.

13. MOTTA, M.G.C. \& ROSSI, N. R. S. Enfermagem pediátrica: assistência de enfermagem pediátrica. Porto Alegre: Saga, 1990, p. 45-51.

14. MORAIS, E. Manif estações de tensão e comportamento de adaptação de crianças hospitalizadas. Rev. Esc. Enf. USP., v. 1, n. 5 , p. $44-57$, mar. 1974.
15. NEIRA, H.E. del P. Interações entre enfermeiras e pais de crianças hospitalizadas. Rev. Esc. Enf. USP, v.1, n. 19, p.81-93, 1985.

16. ; Aprendendo a preparar a criança para enfrentar situações dificeis e/ou desconhecidas. Rev. Esc. Enf. USP, v.1, n. 17, p.27-32, 1983.

17. OKADA, R. M. Comportamento da criança hospitalizada: um parâmetro para assistência de enfermagem. Rev. Esc. Enf. USP., v. 3, n.15, p. 307-312, 1981.

18. RAÑNA, W. Aspectos psicossociais da assistência à criança hospitalizada. Rev. do Centro de Est. Prof. Pedro de Alcantara. Inst da Criança do Hospital das Clínicas do FMUSP. Projeto capricórnio, v. 10, n.2, p.59-66, 1988.

19. RIBEIRO, C. A. Sentido o valor das experiências significativas para aprendizagem: relato de duas situaçòes vividas com crianças hospitalizadas. Rev. Esc. Enf. USP., v.3, n.17, p.159-203, 1983.

20. O efeito da utilização do brinquedo terapêutico para enfermeira pediátrica, sobr eo comportamento de crianças recém-hospitalizdas. Rev. Esc. Enf. USP., v. 25, n.1, p. 41-60, abr. 1991.

21. ROCKENBACH, L.H. A enfermagem e a humanização do paciente. Rev. Bras. Enf., Brasilia, v. 1, n. 38, p. 49-54. jan $/$ mar. 1985.

22. VERÍSSIMO, M. de La Ó R. A experiência de hopitalização explicada pela própria criança. Rev. Esc. USP., v. 25 , n. 2 , p.153-168, ago. 1991. 


\section{ANEXO - FORMULÁRIO}

Apresentação:

Este formulário foi elaborado com o objetivo de levantar dados relativos as crianças em estudo, bem como registrar os comportamentos das mesmas (pré-escolar - 3 a 6 anos) referidas por WHALEY e WONG. As informações serão obtidas pela própria pesquisadora e o sigilo será garantido.

Instruções:

Marcar com " $x$ " os itens que correspondem às características da criança e preercher com letra. legivel os abertos. No item 2.2, deve ser colocado nos parênteses a unidade referente à quertictente específica, e nas questões relativas aos comportamentos das crianças em estudo, na presença e na ausência da mãe duamte o procedimento de venipunção, serão avaliados e registradas as observações.

I. Características Individuais.
1.1. Idade
1.2 Sexo
( ) 4 anos
( ) Masculino
( ) 5 anos
( ) Feminino

II. Hábitos de Vida

Sono:

2.1 No hospital, recusa-se a dormir?

2.1.1 Na primeira fase das observações

2.1.2 Na terceira fase das observações

$\begin{array}{ll}\text { ( ) } \operatorname{Sim} & \text { ( ) Não } \\ \text { ( ) } \operatorname{Sim} & \text { ( ) Não }\end{array}$

2.2 Acorda durante a noite?

2.2.1 Na primeira fase das observações

2.2.2 Na terceira fase das observações

2.3 Tem sono agitado?

2.2.1 Na primeira fase das observações

2.2.2 Na terceira fase das observações

Alimentação

2.4 No hospital, recusa-se a comer?

2.2.1 Na primeira fase das obsenvações

2.2.2 Na terceira fase das observações

2.5 Alimenta-se na ausência da mãe?

2.2.1 Na primeira fase das obsenvações

2.2.2 Na terceira fase das observações

2.6 Alimenta-se com ajuda?

2.2.1 Na primeira fase das observações

2.2.2 Na terceira fase das observações $\begin{array}{ll}\text { ( ) } \operatorname{Sim} & \text { ( ) Não } \\ \text { ( ) } \operatorname{Sim} & \text { ( ) Não }\end{array}$

( ) $\operatorname{Sim}$ ( ) Não

( ) $\operatorname{Sim}$ ( ) Não

( ) $\operatorname{Sim}$ ( ) Não

( ) $\operatorname{Sim}$ ( ) Não 


\section{Comportamentos a Serem Observados}

Reações apresentadas pelas crianças durante o procedimento terapêutico de administração de medicamento por via endovenosa (venipunção).

\begin{tabular}{|c|c|c|c|c|}
\hline \multirow{2}{*}{$\begin{array}{l}\text { AGRESSÃO } \\
\text { FÍSICA }\end{array}$} & \multirow{2}{*}{$\begin{array}{l}\text { Número de } \\
\text { punçס̃es }\end{array}$} & Na presença da máe & Na ausência da måe & \multirow{2}{*}{ OBSERVAÇÕES } \\
\hline & & Sim & Sim & \\
\hline \multirow[t]{2}{*}{ Bate } & $1^{2}$ & & & \\
\hline & $2^{a}$ & & & \\
\hline \multirow[t]{2}{*}{ Chuta } & $1^{2}$ & & & \\
\hline & $2^{a}$ & & & \\
\hline \multirow[t]{2}{*}{ Puxa o braço } & $1^{2}$ & & & \\
\hline & $2^{a}$ & & & \\
\hline \multirow[t]{2}{*}{ Empurra } & $1^{a}$ & & & \\
\hline & $2^{a}$ & & & \\
\hline \multirow{2}{*}{ Segura equipamento } & $1^{a}$ & & & \\
\hline & $2^{a}$ & & & \\
\hline \multirow[t]{2}{*}{ Esconde-se } & $1^{2}$ & & & \\
\hline & $2^{a}$ & & & \\
\hline \multirow[t]{2}{*}{ Joga brinquedo } & $1^{2}$ & & & \\
\hline & $2^{a}$ & & & \\
\hline
\end{tabular}

\begin{tabular}{|c|c|c|c|c|}
\hline \multirow{2}{*}{$\begin{array}{l}\text { EXPRESSĀO } \\
\text { VERBAL }\end{array}$} & \multirow{2}{*}{$\begin{array}{l}\text { Número de } \\
\text { punçठ̌es }\end{array}$} & \multirow{2}{*}{$\begin{array}{c}\text { Na presença da máe } \\
\text { Sim }\end{array}$} & \multirow{2}{*}{$\begin{array}{c}\text { Na ausência da máe } \\
\text { Sim }\end{array}$} & \multirow[b]{2}{*}{ OBSERVAÇŌES } \\
\hline & & & & \\
\hline \multirow[t]{2}{*}{ Chora } & $1^{2}$ & & & \\
\hline & $2^{a}$ & & & \\
\hline \multirow[t]{2}{*}{ Grita } & $1^{2}$ & & & \\
\hline & $2^{a}$ & & & \\
\hline \multirow[t]{2}{*}{ Ameaça } & $1^{2}$ & & & \\
\hline & $2^{\mathrm{a}}$ & & & \\
\hline \multirow[t]{2}{*}{ Discute } & $1^{2}$ & & & \\
\hline & $2^{a}$ & & & \\
\hline \multirow[t]{2}{*}{ Culpa } & $1^{2}$ & & & \\
\hline & $2^{a}$ & & & \\
\hline \multirow[t]{2}{*}{ Exige } & $1^{2}$ & & & \\
\hline & $2^{a}$ & & & \\
\hline
\end{tabular}

\begin{tabular}{|c|c|c|c|c|}
\hline \multirow[b]{2}{*}{ DEPENDÊNCIA } & \multirow{2}{*}{$\begin{array}{l}\text { Número de } \\
\text { punçס̌es }\end{array}$} & \multirow{2}{*}{$\begin{array}{c}\text { Na presença da máe } \\
\text { Sim }\end{array}$} & \multirow{2}{*}{$\begin{array}{c}\text { Na ausência da máe } \\
\text { Sim }\end{array}$} & \multirow[b]{2}{*}{ OBSERVAÇÕES } \\
\hline & & & & \\
\hline \multirow[t]{2}{*}{ Agarra-se aos pais } & $1^{a}$ & & & \\
\hline & $2^{a}$ & & & \\
\hline \multirow[t]{2}{*}{ Chora baixinho } & $1^{a}$ & & & \\
\hline & $2^{a}$ & & & \\
\hline \multirow[t]{2}{*}{ Deseja colo } & $1^{\mathrm{a}}$ & & & \\
\hline & $2^{a}$ & & & \\
\hline \multirow[t]{2}{*}{ Recusa-se a brincar } & $1^{\mathrm{a}}$ & & & \\
\hline & $2^{a}$ & & & \\
\hline \multirow{2}{*}{$\begin{array}{l}\text { Recusa-se a ficar } \\
\text { sozinho }\end{array}$} & $1^{2}$ & & & \\
\hline & $2^{\mathrm{a}}$ & & & \\
\hline
\end{tabular}

